\title{
Correlation between Protective Immunity to $\alpha$-Synuclein Aggregates, Oxidative Stress and Inflammation
}

\author{
Marina A. Gruden ${ }^{a}$ Kiran Yanamandra ${ }^{d}$ Valery G. Kucheryanu ${ }^{b}$ \\ Olga R. Bocharovac Vladimir V. Sherstnev ${ }^{\text {a }}$ Ludmilla A. Morozova-Roche $^{d}$ \\ Robert D.E. Sewelle

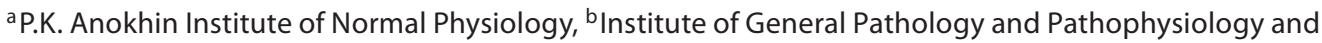 \\ ${ }^{c}$ N.N. Blokhin Russian Cancer Research Center, Russian Academy of Medical Sciences, Moscow, Russia; \\ ${ }^{\mathrm{d}}$ Department of Medical Biochemistry and Biophysics, Umeå University, Umeå, Sweden; ${ }^{\mathrm{e}}$ Cardiff School of \\ Pharmacy and Pharmaceutical Sciences, Cardiff University, Cardiff, UK
}

\section{Key Words}

Parkinson's disease $\cdot \alpha$-Synuclein oligomers .

Autoantibodies $\cdot$ Cytokines $\cdot$ Oxidative stress

\begin{abstract}
Objective: Protein aggregation leading to central amyloid deposition is implicated in Parkinson's disease (PD). During disease progression, inflammation and oxidative stress may well invoke humoral immunity against pathological aggregates of PD-associated $\alpha$-synuclein. The aim was to investigate any possible concurrence between autoimmune responses to $\alpha$-synuclein monomers, oligomers or fibrils with oxidative stress and inflammation. Methods: The formation of $\alpha$-synuclein amyloid species was assessed by thioflavin- $T$ assay and atomic force microscopy was employed to confirm their morphology. Serum autoantibody titers to $\alpha$-synuclein conformations were determined by ELISA. Enzyme activity and concentrations of oxidative stress/inflammatory indicators were evaluated by enzyme and ELISA protocols. Results: In PD patient sera, a differential increase in autoantibody titers to $\alpha$-synuclein monomers, toxic oligomers or fibrils was associated with boosted levels of the pro-inflammatory cytokine interleukin- 6 and tumour necrosis factor- $\alpha$, but a de-
\end{abstract}

crease in interferon- $\gamma$ concentration. In addition, levels of malondialdehyde were elevated whilst those of glutathione were reduced along with decrements in the activity of the antioxidants: superoxide dismutase, catalase and glutathione transferase. Conclusions: It is hypothesized that the generation of $\alpha$-synuclein amyloid aggregates allied with oxidative stress and inflammatory reactions may invoke humoral immunity protecting against dopaminergic neuronal death. Hence, humoral immunity is a common integrative factor throughout PD progression which is directed towards prevention of further neurodegeneration, so potential treatment strategies should attempt to maintain PD patient immune status.

Copyright $\odot 2012$ S. Karger AG, Basel

\section{Introduction}

The increased levels of monomeric and oligomeric species of $\alpha$-synuclein may be promising bioindicators of the pathological conditions occurring in Parkinson's disease (PD) [1]. It has also been demonstrated that prefibrillar aggregates of $\alpha$-synuclein, similar to other amyloid species, are candidates as generic toxins [2]. During PD

\section{KARGER \\ Fax +4161306 1234 \\ E-Mail karger@karger.ch}

www.karger.com
(C) 2012 S. Karger AG, Basel

$1021-7401 / 12 / 0196-0334 \$ 38.00 / 0$

Accessible online at:

www.karger.com/nim
Robert D.E. Sewell

Cardiff School of Pharmacy and Pharmaceutical Sciences, Cardiff University

Redwood Building, King Edward VII Ave, Cathays Park

Cardiff CF10 3NB (UK)

Tel. +44292087 5821, E-Mail sewell@ cardiff.ac.uk 
progression, there is a complex of interrelated pathological conditions involving humoral and cellular immunity [3-5] arising from oxidative stress and inflammation [68 ] which are forerunners of the protein misfolding cascade [9]. Oxidative stress may not only result in neuroinflammation, but also in the formation of poorly degraded proteins stemming from the actions of reactive oxygen species (ROS) or nitrogen species which favour the misfolding of $\alpha$-synuclein [7]. On the other hand, dopaminergic neurodegeneration may arise partially from the modulation of glial function as a result of elevated soluble or insoluble $\alpha$-synuclein released from affected neurons in Lewy bodies. $\alpha$-Synuclein is nitrated during oxidative stress, and in its aggregated form, it incites microglial inflammation [10]. These processes, during the initial degenerative stages of parkinsonism, may possibly instigate compensatory immunological consequences [11]. Raised levels of oligomeric forms of $\alpha$-synuclein have been described in the plasma of PD patients [12]. Subsequently, we have focused on autoimmune reactions towards aberrant antigens involved in PD which could serve as sensitive indicators of subtle shifts in biochemical processes occurring during the initial stages of the disease pathogenesis. Accordingly, elevated concentrations of toxic misfolded protein species may potentially modify natural autoimmunity in humans [3-5, 13-15], suggesting a protective role of autoimmunity in PD [3]. In this study, we undertake endeavours to ascertain possible interrelationships between autoimmune responses to biomarkers such as monomeric, toxic oligomeric or fibrillar forms of $\alpha$ synuclein and the main indicators of oxidative stress and inflammation in PD.

\section{Methods}

\section{Human Subjects}

PD patients $(\mathrm{n}=38)$ of either gender (22 males and 16 females $)$ within the age range $43-78$ years (mean $62.7 \pm 2.3$ ) were recruited from the Russian Research Center of Neurology of the Russian Academy of Medical Sciences. Patients underwent neurological examination and were diagnosed with PD and classified according to their disease severity by the Unified PD Rating Scale (UPDRS) [16]. Patient scores ranged from 1 to 4 , the majority being grade 2 on the Hoehn and Yahr scale [17]. Both patient and control group demographics are shown in table 1 . The interval after diagnosis was $\leq 5$ years. Eighteen PD patients presented primarily with tremor accompanied by rigidity, while 19 possessed predominantly rigidity along with tremor and 1 individual was diagnosed with the akinetic rigid form of the disease (i.e. all patients were in the off phase of the on-off cycle) (table 2). All patients were treated with dopaminergic-based antiparkinsonian therapy including the L-DOPA dopamine (DA) precursor agents L-Dopa +
Table 1. Group characteristics of the study population

\begin{tabular}{lcc}
\hline Group characteristics & $\begin{array}{c}\text { PD patients } \\
(\mathrm{n}=32)\end{array}$ & $\begin{array}{l}\text { Controls } \\
(\mathrm{n}=26)\end{array}$ \\
\hline Age, years & $60.8 \pm 2.0$ & $63.0 \pm 3.0$ \\
Male:female & $20: 12$ & $19: 7$ \\
Age at onset of PD, years & $60.8 \pm 2.0$ & - \\
Duration of PD, years & $1-5$ & - \\
UPDRS motor score & $23.3 \pm 1.9$ & - \\
Hoehn and Yahr stage & $2.1 \pm 0.6$ & - \\
\hline
\end{tabular}

Data of quantitative variables are expressed as group mean \pm SEM.

Table 2. Clinical analysis of PD patients by UPDRS

\begin{tabular}{lc} 
Clinical components of UPDRS & UPDRS score (mean \pm SEM) \\
\hline Impairment of daily activity & $18.7 \pm 1.6$ \\
Motor activity & $23.3 \pm 1.9$ \\
Tremor & $2.3 \pm 0.13$ \\
Rigidity & $2.2 \pm 0.14$ \\
Bradykinesia & $2.0 \pm 0.18$ \\
\hline
\end{tabular}

carbidopa (Sinemet $\mathrm{CR}^{\circledR}$ or Nacom ${ }^{\circledR}$ ) or L-Dopa + benserazide $\left(\right.$ Madopar $\left.^{\circledR}\right)$, the non-ergot D2/D3 agonists Piribedil (Pronoran ${ }^{\circledR}$ ) or pramipexole (Miropex ${ }^{\circledR}$ ). The mean group dose for L-Dopa over $4.2 \pm 0.7$ treatment years was $411.5 \pm 134.6 \mathrm{~g} /$ patient.

Patients with concomitant neurological or psychiatric diseases, cancer and other severe diseases were excluded. Healthy agematched control individuals $(n=26)$ were selected and the exclusion criteria were identical to those for PD patients. All patients and control subjects gave their informed consent to participate in the study, which was conducted in accord with the provisions of the World Medical Association Declaration of Helsinki (2000).

Source and Preparation of Samples

$\alpha$-Synuclein was purchased from Millipore, USA. Blood samples $(5 \mathrm{ml})$ from all patients and controls were collected without additives. After $1 \mathrm{~h}$ of coagulation, samples were centrifuged for $15 \mathrm{~min}$ at $3,500 \mathrm{~g}\left(4^{\circ} \mathrm{C}\right)$. The sera were collected, aliquoted into Eppendorf tubes, frozen immediately and stored at $-80^{\circ} \mathrm{C}$, before being defrosted and subjected to a range of biochemical analyses.

\section{Production of $\alpha$-Synuclein Amyloidogenic Species}

In order to produce cytotoxic amyloid oligomers [4, 18], $\alpha$ synuclein $(3 \mathrm{mg} / \mathrm{ml})$ was incubated in $10 \mathrm{mM} \mathrm{Na}_{2} \mathrm{HPO}_{4}$ at $\mathrm{pH} 7.4$ and $37^{\circ} \mathrm{C}$ with continuous agitation at $300 \mathrm{rpm}$ for 7 days and fibrils for 14 days.

ELISA of Serum Antibodies to Monomers, Oligomers and Fibrils of $\alpha$-Synuclein

The titers of serum antibodies to $\alpha$-synuclein monomers oligomers and fibrils were determined by ELISA $[4,19]$ in 96-well 
polysterol plates (Costar, USA) using 6 repetitions per sample. Microtiter wells were coated with the antigens at concentrations of 15.0, 20.0, $20.0 \mu \mathrm{g} / \mathrm{ml}$, respectively, in $50 \mathrm{mM}$ phosphate buffer, $\mathrm{pH} 8.0$ ( $4^{\circ} \mathrm{C}$ overnight). The plates were washed 3 times with phosphate-buffered saline (PBS) plus $0.05 \%$ Tween 20, blocked with $1 \%$ w/v BSA in PBS, pH 7.5 (Sigma, USA) for $2 \mathrm{~h}\left(4^{\circ} \mathrm{C}\right)$ and washed with $\mathrm{PBS}$ plus $0.05 \%$ Tween 20 . The coated plates were incubated for $16 \mathrm{~h}\left(6^{\circ} \mathrm{C}\right)$ with the samples of PD-patient serum using 2 -fold serial dilutions in PBS, over the dilution range 1:2 up to 1:3,000. The plates were then washed 6 times with PBS plus $0.05 \%$ Tween 20 , and serum antibody-antigen interactions were identified during incubation for $2 \mathrm{~h}$ at $37^{\circ} \mathrm{C}$ using horseradish peroxidase conjugated with goat antibodies to human immunoglobulins (IgG) (Amersham, UK) at a dilution of 1:1,000. The plates were subsequently washed 6 times and incubated for $30 \mathrm{~min}$ with $o$-phenylenediamine (Sigma, USA) as substrate in the enzyme reaction. Absorbance at $450 \mathrm{~nm}$ was measured using the plate reader (Flow Lab., USA). The titer of each serum sample was derived from the reciprocal of the greatest dilution at which the enzyme-substrate reaction gave an optical density value greater than that of the mean optical density of blanks. The values of titers at which we observed immunoreactivity to the antigens were represented in relative dilution ratio units. The titer of each serum sample was derived from the reciprocal of the greatest dilution at which the enzyme-substrate reaction gave an optical density value greater than that of the mean optical density of blanks.

ELISA of Interleukin-6, Tumour Factor- $\alpha$ and Interferon- $\gamma$

ELISA was performed by formal protocols using commercial kits in order to verify the levels of cytokines interleukin-6 (IL-6; Bioscience, UK), tumour necrosis factor- $\alpha$ (TNF- $\alpha$ ) and interferon- $\gamma$ (IFN- $\gamma$; Cytokine, Russia) in all blood samples.

\section{Measurement of Oxidative Stress Indicators}

The concentration of malondialdehyde (as an end-product of lipid peroxidation or as a by-product of arachidonic acid metabolism) was determined by the method of Mihara and Uchiyama [20]. Using methods reported by Beauchamp and Fridovich [21] the activity of other oxidative stress indicators which included the antioxidants superoxide dismutase, catalase, glutathione S-transferase and the concentration of total glutathione were determined, respectively [21-24].

\section{Atomic Force Microscopy}

The morphology of amyloid species of $\alpha$-synuclein was examined by means of a PICO PLUS atomic force microscope (Agilent, USA) in a non-contact mode using a $100-\mu \mathrm{m}$ scanner with acoustically (air)-driven cantilevers employing imaging procedures as described previously [25]. A scanner with a $100-\mu \mathrm{m}$ scan size and cantilevers carrying 10-nm-diameter etched silicon probes of the TESP model (Veeco, The Netherlands) were applied. Scanning was performed at a resonance frequency in the $312-340 \mathrm{kHz}$ range, a scan rate of $1 \mathrm{~Hz}$ and with a resolution of $512 \times 512$ pixels. Height, amplitude and phase data were collected simultaneously. Images were flattened and the plane adjusted. The scanning of samples was performed in trace and retrace to avoid scan artifacts. The scanner was calibrated by measuring atomic steps on highly orientated pyrolytic graphite in the $z$-axis and using a standard $1-\mu \mathrm{m}$ calibration grid (Agilent, USA) in the $x y$ plane. For imaging in air, protein samples were incubated for $30 \mathrm{~min}$ on freshly cleaved mica, washed with MiliQ water $(3 \times 100 \mu \mathrm{l})$ and dried overnight at room temperature. The distribution of dimensions of the amyloid species was measured in atomic force microscopy (AFM) cross sections.

\section{Thioflavin-T Amyloid Binding Assay}

The formation of amyloid oligomers was assessed using thioflavin-T dye binding assay, employing a modification of the method described previously [26]. The fluorescence measurements were performed on a Jasco FP-6500 spectrofluorometer (Jasco, Japan). The dye was excited at $440 \mathrm{~nm}$ and emission spectra were recorded between $450-550 \mathrm{~nm}$, setting the excitation and emission slits at $3 \mathrm{~nm}$.

\section{Statistical Analysis}

Comparison between groups was carried out non-parametrically using the Mann-Whitney test and the 2-tailed Student t test for unequal variance. Spearman's coefficient was used to evaluate the correlation between two variables.

\section{Results}

\section{Characterization of $\alpha$-Synuclein Oligomeric and}

\section{Fibrillar Species}

Oligomeric species of $\alpha$-synuclein were produced at $\mathrm{pH} 7.4$ with agitation and characterized by the thioflavinT binding assay and then AFM analysis prior to ELISA, which was particularly important since amyloid species display an inherent diversity of structures dependent on solution conditions. The samples containing oligomers were collected at the end of the lag phase (7 days), at which time a detectable fluorescence increase was observed, as shown in figure $1 \mathrm{~d}$, indicative of cross- $\beta$-sheet formation. The oligomers were characterized by a round-shaped morphology assessed by AFM imaging (fig. 1a). The distribution of oligomeric particle heights measured in AFM cross sections is shown in figure $1 \mathrm{~b}$. They were represented by a wide range of species with heights from 1.2 to 3.9 $\mathrm{nm}$. Their maximal population was centered around species with approximately 1.8 - to 2 -nm heights, which corresponded to 20-mers (as estimated previously [25]) and the oligomeric nature of these species has been verified by interaction with generic A11 antibodies reactive towards amyloid oligomers [4].

Mature fibrils were developed after 14 days of incubation and were characterized by a 10 -fold increase in thioflavin-T fluorescence intensity (fig. 1d) and displayed typical fibrillar morphology with up to a micron in length. They were constituted by a few single stranded protofilaments intertwined around each other and resulting in structures of $8-10 \mathrm{~nm}$ in height measured by AFM cross-section analysis (fig. 1c). 

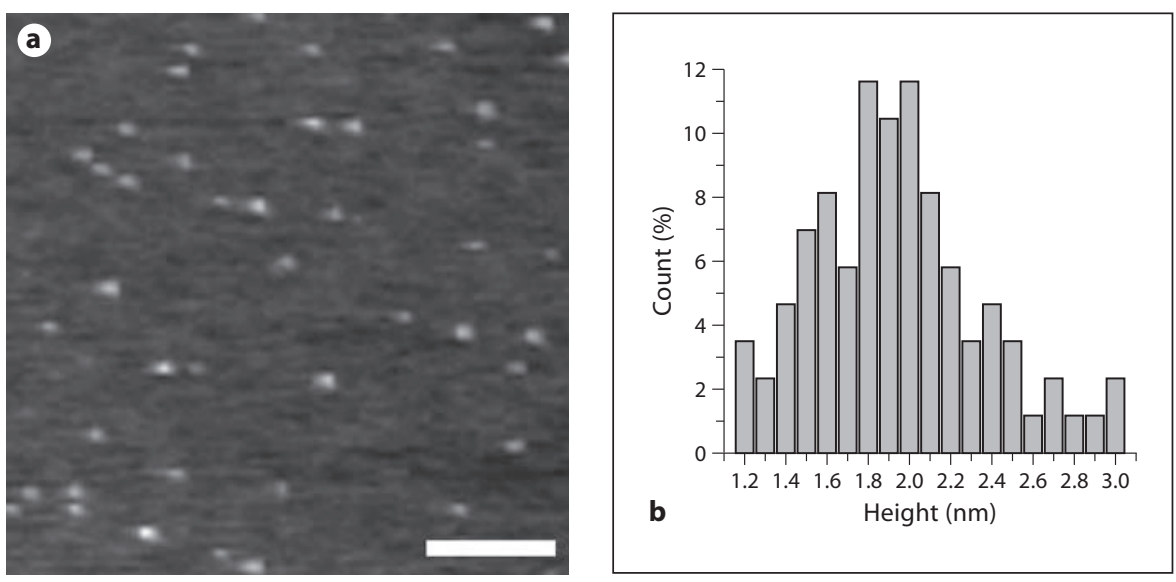

Fig. 1. AFM imaging and thioflavin-T fluorescence assay of $\alpha$-synuclein amyloid species produced in sodium phosphate buffer $\mathrm{pH} 7.4$ at $22^{\circ} \mathrm{C}$ with agitation. a AFM height image of amyloid oligomers formed after 7 days of incubation. $\mathbf{b}$ Distribution of the heights of oligomeric species measured by AFM crosssection analysis. c AFM height image of amyloid fibrils of $\alpha$-synuclein produced under the same conditions after 14 days of incubation. d Thioflavin-T fluorescence intensities measured at $480 \mathrm{~nm}$ in the presence of monomeric $\alpha$-synuclein, amyloid oligomers and fibrils, respectively.
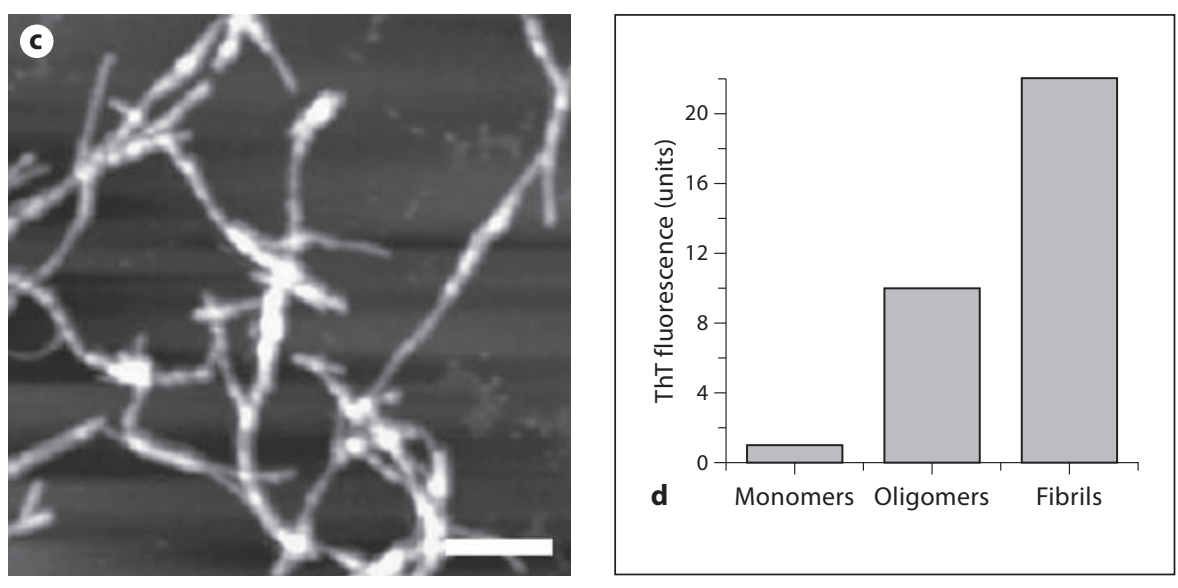

Autoimmune Responses to $\alpha$-Synuclein Monomers, Oligomers and Fibrils in PD Patients

Antibodies to monomers, oligomers and fibrils of $\alpha$ synuclein were subjected to immune analysis in the sera of PD sufferers ( $\leq 5$ years duration) versus age-matched control subjects. Control and PD serum IgG representative titration curves towards 3 types of $\alpha$-synuclein states as the antigens have been reported previously by these laboratories [4]. The comparative results of ELISA analysis of immune-reactivity to $\alpha$-synuclein monomers and oligomers in the blood sera of patients and controls are presented in figure 2 . These observations demonstrate that in healthy individuals the immune responses towards monomeric $\alpha$-synuclein were at the titer cut-off level for ELISA, displaying a very narrow distribution of titers. In contrast, in early PD patients there was a significant increase in IgG reactivity towards $\alpha$-synuclein monomers ( $p<$ 0.0001 ). There was a wider range of immune responses in this group than in controls with $72 \%$ of patients displaying high immune reactivity towards this $\alpha$-synuclein spe- cies. It is important to note that 3 individuals displayed particularly high responses, with up to a 25 -fold enhancement in the $\operatorname{IgG} \alpha$-synuclein reactivity as estimated by their titers. A significant $(p<0.05) 17$-fold increase in autoimmune reactivity towards $\alpha$-synuclein monomers compared to controls was observed and, as might be predicted, the variability of this response was greater than in the controls. Titers of autoantibodies to oligomeric species of $\alpha$-synuclein in approximately $50 \%$ of the patient sera were 4 -fold higher than the control group. A doubling of titer values to fibrillar $\alpha$-synuclein species was seen in only $17 \%$ of patients with respect to controls, but there was no significance $(\mathrm{p}>0.05)$ to this observation and antibody titers to this protein aggregate remained generally low throughout, so the data was not shown.

Overall, it is clear that all PD patients displayed elevated levels of serum autoantibodies to $\alpha$-synuclein biochemical markers up to 5 years after disease diagnosis. Moreover, there was no correlation between the autoimmune reactivity to any of the biomarkers with respect to 
age or gender ( $p=0.1$ which is above $p=0.05$ set as the significance level) (data not shown).

\section{Indicators of Oxidative/Antioxidative Processes}

(Oxidative Stress) in PD Patients

The blood concentration of malondialdehyde, as a marker of oxidative stress, was $58.1 \%$ higher whilst glutathione decreased $(-17.6 \%)$ in the entire PD patient group when compared to the age-matched controls (table 3). There was also a reduction of antioxidant activity as indicated by decrements in superoxide dismutase $(-22.6 \%)$, catalase $(-4.6 \%)$, and glutathione transferase $(-14.3 \%)$ in PD blood. These findings could be viewed as evidence of a predominance of oxidative over antioxidant processes in the current PD conditions.

\section{Serum Cytokine Content in PD Patients}

In comparison to controls, all PD patients disclosed boosted levels of the pro-inflammatory cytokines IL-6 $(+444.4 \%)$ and TNF- $\alpha$ (+153.3\%). In contrast, the antiinflammatory cytokine INF- $\gamma$ was decreased by $99.8 \%$ (table 4). Taken together, these data suggest that there was a general activation of inflammatory mechanisms in the PD patients studied.

\section{Discussion}

Autoantibodies with specificity to self-antigens including amyloidogenic proteins have been associated with a broad diversity of neurological diseases [4, 14, 15, 27-29]. It is important to note that amyloid-reactive IgGs are naturally present in the blood sera of healthy individuals, recognizing the common conformational epitope of amyloid fibrils, regardless of their protein composition [30, 31]. It should also be recognized that more than $99 \%$ of monomeric $\alpha$-synuclein in human blood is present in peripheral blood cells with the remainder being in plasma [32]. In this study, serum was employed as the sample body fluid, thus minimizing any erythrocyte-derived $\alpha$-synuclein contaminant level in the samples. In addition, comparison of age-matched control samples with PD samples would tend to negate the $\alpha$-synuclein background. We observed a substantial rise in antibody reactivity against $\alpha$ synuclein monomers in PD sera and this effect was considerably larger than the increase in antibodies against $\alpha$ synuclein oligomers (fig. 2). Since amyloid formation is a concentration-dependent process, any increase in $\alpha$ synuclein production or a disbalance in protein metabolism is likely to be an amyloid-prone factor. Therefore, the

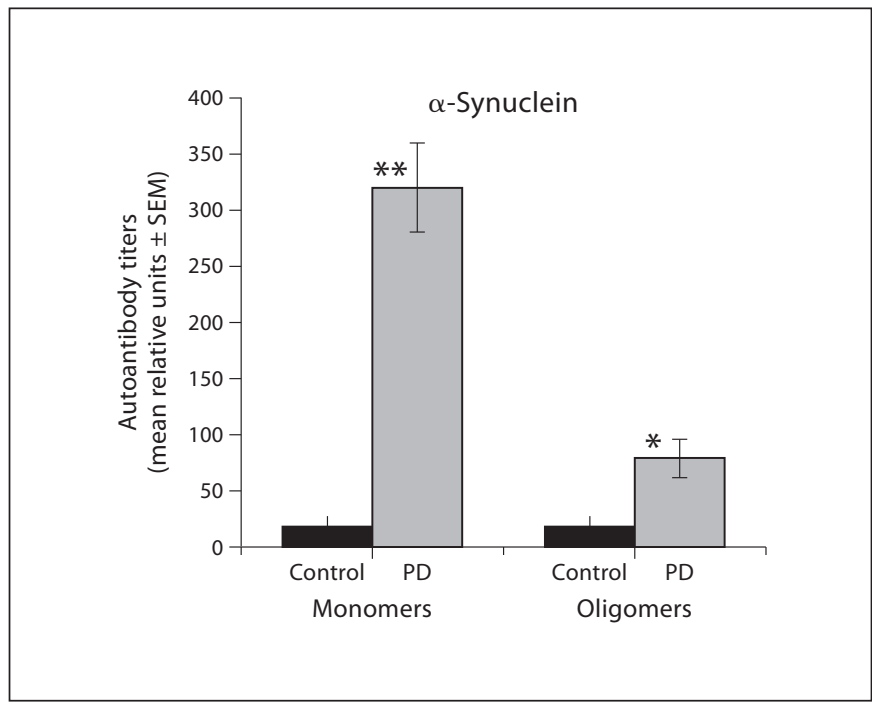

Fig. 2. Titers of serum antibodies (relative dilution ratios) to $\alpha$ synuclein monomers and $\alpha$-synuclein amyloid oligomers in control patients (black columns) and PD patients (hatched columns) with $\leq 5$-year disease duration, respectively. ${ }^{*} \mathrm{p}<0.05$ and ${ }^{* *} \mathrm{p}<$ 0.01 .

humoral clearance of monomeric precursor will ultimately constrain the formation of toxic oligomeric species. It has also been shown that overexpression of $\alpha$-synuclein during the presymptomatic stage of PD is implicated in early changes in synaptic DA release and synaptic dysfunction, triggering disease progression [33]. On the other hand, the most pathogenic oligomeric species of $\alpha$ synuclein are highly heterogeneous, as shown in the distribution of their sizes in figure $1 \mathrm{~b}$, and they are transient in nature. They populate the pathway to fibril formation and can undergo rapid oligomeric inter-conversion or progress to generate larger fibrillar structures. We have measured the immunoreactivity to the whole ensemble of amyloid oligomers and the possibility cannot be excluded that autoimmunity is able to differentiate between pathogenic species and bystanders. Taken together, these facts further emphasize the significance of monomer clearance by humoral immunity as a protective measure against cellular toxicity and degeneration.

We wished to gain an additional insight into any congruence in relation to inflammation, oxidative stress and humoral immunity towards disease-linked protein misfolding in PD. Hence, we analyzed the autoantibodies to native and amyloidogenic species of $\alpha$-synuclein simultaneously in patient sera as PD biomarkers along with the activity of antioxidant enzymes, malondialdehyde con- 
Table 3. Indicators of oxidative stress status in PD patients

\begin{tabular}{|c|c|c|c|c|c|}
\hline \multirow[t]{2}{*}{ Oxidative stress indicator } & \multicolumn{2}{|l|}{ Controls } & \multicolumn{3}{|c|}{ PD patients } \\
\hline & $\begin{array}{l}\text { concentra- } \\
\text { tion }\end{array}$ & enzyme activity & $\begin{array}{l}\text { concentra- } \\
\text { tion }\end{array}$ & enzyme activity & $\%$ change \\
\hline Malondialdehyde, $\mu \mathrm{M} / \mathrm{l}$ & $4.3 \pm 0.1$ & - & $6.8 \pm 0.3^{*}$ & - & +58.1 \\
\hline Superoxide dismutase, $\mathrm{U} / \mathrm{ml} / \mathrm{min}$ & - & $420.2 \pm 18.5$ & - & $325.1 \pm 20.4^{*}$ & -22.6 \\
\hline Catalase, $\mathrm{U} / \mathrm{ml} / \mathrm{min}$ & - & $32.8 \pm 0.9$ & - & $31.3 \pm 1.5$ & -4.6 \\
\hline Glutathione, $\mu \mathrm{M} / \mathrm{l}$ & $1.7 \pm 0.1$ & - & $1.4 \pm 0.1^{*}$ & - & -17.6 \\
\hline Glutathione S-transferase (antiox.), $\mu \mathrm{M} / \mathrm{ml} / \mathrm{min}$ & - & $1.4 \pm 0.06$ & - & $1.2 \pm 0.1^{*}$ & -14.3 \\
\hline
\end{tabular}

${ }^{\star} \mathrm{p}<0.05$, difference from control group values. antiox. $=$ Antioxidant.

Table 4. Blood concentration (pg/ml) of cytokines in PD patients and controls

\begin{tabular}{llll}
\hline Cytokines & $\begin{array}{l}\text { Controls } \\
\text { pg/ml } \\
(\text { mean } \pm \text { SEM) }\end{array}$ & $\begin{array}{l}\text { PD/ml patients } \\
\text { (mean } \pm \text { SEM) }\end{array}$ & \\
\hline IL-6 & $7.2 \pm 1.2$ & $39.2 \pm 3.0^{*}$ & +444.4 \\
TNF- $\alpha$ & $1.5 \pm 0.7$ & $3.8 \pm 1.8^{*}$ & +153.3 \\
INF- $\gamma$ & $12.5 \pm 2.8$ & $0.09 \pm 0.04^{*}$ & -99.8 \\
\hline
\end{tabular}

${ }^{*} \mathrm{p}<0.05$, difference from control values.

centration and cytokine levels as significant oxidative stress and inflammatory indicators [34]. In normal physiological conditions, $\alpha$-synuclein exists intrinsically as an unfolded protein, but during altered conditions in vitro and in vivo, it may self-assemble to form ordered fibrillar aggregates [35] characterized by a cross- $\beta$-sheet structure similar to the aggregates found in Lewy bodies [36]. It is interesting that the initial phase of the $\alpha$-synuclein aggregation process is thought to involve the formation of oligomeric species which possess a much higher degree of cytotoxicity than the mature fibrils into which they develop $[1,4,37]$. How $\alpha$-synuclein species cause neurodegeneration is currently unknown, but increased expression of this protein is associated with elevated susceptibility of cells to oxidative stress, DA toxicity and apoptosis [38]. We have found that during the early stages of the disease, the immune clearance system targets not only the amyloid forms of disease-associated amyloid- $\beta$ peptide [39], but also lysozyme, which is not related to AD pathology [14]. More recently, a linked triad between olfactory impairment, autoimmunity and neurodegenerative dis- eases like PD has been described [40]. Moreover, we have shown that processes of $\alpha$-synuclein misfolding and the appearance of toxic aggregates may invoke humoral immunity in the pathological gambit causing dopaminergic neuronal death in PD $[4,15]$. It has also been demonstrated that in terms of cellular immunity in PD, there is a decay of lymphocyte subsets which reflects the influence of inflammatory and oxidative stress reactions [3].

Multi-epitopic autoantibodies against $\alpha$-synuclein have been detected in $65 \%$ of PD patients with an inherited mode of the disease [29]. Moreover, during mice immunization by $\alpha$-synuclein, in those animals which produced high-affinity antibodies, there was also a decreased accumulation of aggregated $\alpha$-synuclein in neuronal cell bodies and synapses that were associated with reduced neurodegeneration. Furthermore, antibodies produced by immunized mice recognized abnormal $\alpha$-synuclein associated with neuronal membranes and promoted the degradation of $\alpha$-synuclein aggregates, probably via lysosomal pathways. Similar effects were observed with an exogenously applied FITC-tagged $\alpha$-synuclein antibody [41]. There is a biphasic profile of idiotypic antibody generation to disease-linked proteins and it has also been found that constituents of the classical or antibody-triggered complement cascade occur in Lewy bodies [42]. This evidence substantiates the finding that pathological conditions in PD engage central humoral immunity mechanisms [43]. Thus, in the brain tissue of PD patients, there were significant levels of immunoglobulin $G$ which bound to DA neurons in a concentrated distribution at neuronal surfaces or on Lewy bodies co-localized with $\alpha$-synuclein [43]. Moreover, initiation of humoral immunity in early onset PD may also be concomitant with the instigation of inflammatory processes which play a fundamental role in the pathogenesis of parkinsonism [44]. 
It has become increasingly evident that inflammatory and oxidative stress processes play prominent roles in amyloid-related neurodegenerative diseases in general, including Alzheimer's and prion diseases [45-47]. These processes are sustained mainly by activated microglia and astrocytes, which in response to the pathogenic event, over-secrete bioactive molecules. Thus, amyloidgenic peptides and proteins such as amyloid- $\beta$ fragments and their amyloid species as well as prions activate microglia and astrocytes inducing secretion of a specific range of cytokines and chemokines (IL-1, IL-6, IL-12, TNF- $\alpha$ and others) in addition to ROS $[48,49]$. In both Alzheimer's and prion diseases, amyloid depositions cause recruitment of proliferating astrocytes and phagocytic microglia. These activated cells may well contribute to the clearance of potentially toxic species, though uncontrollable glial activation may actually exacerbate neuronal damage via prolonged release of inflammatory cytokines, ROS and other diffusible factors [47, 50, 51]. In $\mathrm{PD}$, during these conditions, release of DA may also activate microglia to generate pro-inflammatory cytokines (IL- 6 and TNF- $\alpha$ measured peripherally) and a decline in INF- $\gamma$ content $[52,53]$. Our results have at least demonstrated parallel phenomena which would concur with the literature in relation to the generating of $\alpha$-synuclein aggregate antibody in parkinsonism. It might be hypothesized that there is a protective role for idiotypic autoantibodies to toxic oligomeric species of $\alpha$-synuclein with the purpose of abolishing the toxic effects of aggregates towards dopaminergic cells in the substantia nigra and other brain regions pertinent to pathology.

Furthermore, oxidative stress has been implicated in the pathogenesis of $\mathrm{PD}$ as a result of its role in the cascade of biochemical changes that lead to dopaminergic neuronal death [54]. Graham [55] reported that DA can autooxidize at normal physiological $\mathrm{pH}$ to form toxic $\mathrm{ROS}$ such as hydroxyl radicals, superoxide anions and DAquinone species. These ROS are capable of oxidizing DNA, proteins and lipids to modify their biofunctions, for instance, by boosting membrane permeability, thereby intensifying any cell damage $[6,9]$. Subsequently, ROS may form covalent adducts with $\alpha$-synuclein to inhibit the generation of fibrils from oligomeric species, thereby increasing toxicity [56]. This oxidative burden, under normal conditions, is kept in check by antioxidant systems and also by the fact that free DA is loaded into vesicles for enzymatic protection [57]. At the asymptomatic stage of PD when oxidative stress initiates the formation of $\alpha$-synuclein amyloidogenic species, humoral immunity actively protects dopaminergic neurons in the sub- stantia nigra and other brain regions from $\alpha$-synuclein oligomeric toxicity by producing autoantibodies not only to DA and other disease biomarkers [15], but also toxic to $\alpha$-synuclein oligomers themselves. As PD progresses ( $\geq 50 \%$ dopaminergic neuronal loss), autoantibodybinding to DA results in a relative lack of antioxidant activity, so as a consequence, autoimmunity fails to cope with oxidative stress and cytotoxicity. In this study, analysis of oxidant/antioxidant regulators suggested that the balance was shifted towards oxidative stress as evidenced by the increased content of such a highly reactive oxidative stress marker as malondialdehude and diminished levels of glutathione as well as the activity of superoxide dismutase, catalase and other indicators of the antioxidant system that normally inactivate ROS. The findings concur with earlier reported deficits in neural antioxidants and detoxification mechanisms in this disease [58] as well as the presence of high oxidative stress as measured by carbonyl protein levels [59]. The data are also in accord with the results of Lotharius and Brundin [57] who substantiated the need for antioxidative systems in PD prevention.

In conclusion, $\alpha$-synuclein misfolding and the generation of toxic aggregates in PD are linked to a combination of inflammatory processes, ROS and invoked humoral immunity as a protective response. We suggest that the concurrence between amyloid self-assembly, humoral responses to amyloidgenic protein and amyloid species, oxidative stress and pro-inflammatory cytokine levels in $\mathrm{PD}$ as well as in other amyloid-related neurodegenerative diseases is not merely circumstantial, but reflects complex interconnected pathological processes causing disease progression. The differential production of monomer and amyloid specific antibodies appears to reflect the continuum from non-toxic to toxic species and this might be exploited as a diagnostic tool for neurodegenerative states. Moreover, humoral immunity is a common integrative factor throughout $\mathrm{PD}$ progression which is directed towards prevention of further neurodegeneration, hence potential treatment strategies should attempt to maintain $\mathrm{PD}$ patient immune status.

\section{Acknowledgements}

We wish to thank Dr. Vsevolod V. Polyschuk from the Russian Research Center of Neurology, RAMS, Moscow, for access to patients, and Elena I. Elistratova for technical assistance provided throughout the study. L.A.M.R. thanks the Swedish Medical Research Council and Insamlingsstiftelsen, Umeå, for financial support. 


\section{References}

1 Yu J, Lyubchenko Y: Early stages for Parkinson's development: alpha-synuclein misfolding and aggregation. J Neuroimmune Pharmacol 2009;4:10-16.

$>2$ Baglioni S, Casamenti F, Bucciantini M, Luheshi LM, Taddei N, Chiti F, Dobson CM, Stefani M: Prefibrillar amyloid aggregates could be generic toxins in higher organisms. J Neurosci 2006;26:8160-8167.

$>3$ Gruden MA, Sewell RDE, Yanamandra K, Davidova TV, Kucheryanu VG, Bocharov EV, Bocharova OR, Polyschuk VV, Sherstnev VV, Morozova-Roche LA: Immunoprotection against toxic biomarkers is retained during Parkinson's disease progression. J Neuroimmunol 2011;233:221-227.

-4 Yanamandra K, Gruden MA, Casaite V, Meskys R, Forsgren L, Morozova-Roche LA: $\alpha$-Synuclein reactive antibodies as diagnostic biomarkers in blood sera of Parkinson's disease patients. PLoS One 2011;6:e18513.

$\checkmark 5$ Roodveldt C, Christodoulou J, Dobson CM: Immunological features of alpha-synuclein in Parkinson's disease. J Cell Mol Med 2008; 12:1820-1829.

6 Younes-Mhenni S, Frih-Ayed M, Kerkeni A, Bost M, Chazot G: Peripheral blood markers of oxidative stress in Parkinson's disease. Eur Neurol 2007;58:78-83.

$>7$ Gao HM, Kotzbauer PT, Uryu K, Leight S, Trojanowski JQ, Lee VM: Neuroinflammation and oxidation/nitration of alpha-synuclein linked to dopaminergic neurodegeneration. J Neurosci 2008;28:7687-7698.

8 Whitton PS: Inflammation as a causative factor in the aetiology of Parkinson's disease. Br J Pharmacol 2007;50:963-976.

9 Foltynie T, Michell AW, Barker RA: Parkinson's disease: What is it? What causes it? And how can it be cured? in Smith HJ, Simonds C, Sewell RDE (eds): Protein Misfolding in Neurodegenerative Diseases. Boca Raton, CRC Press, 2008, pp 381-414.

$\checkmark 10$ Reynolds AD, Glanzer JG, Kadiu I, RicardoDukelow M, Chaudhuri A, Ciborowski P, Cerny R, Gelman B, Thomas MP, Mosley RL, Gendelman HE: Nitrated alpha-synucleinactivated microglial profiling for Parkinson's disease. J Neurochem 2008;104:15041525.

11 Czionkowska A, Kurkowska-Jastrzebska I, Czionkowski A, Peter D, Stefano GB: Immune processes in the pathogenesis of Parkinson's disease - a potential role for microglia and nitric oxide. Med Sci Monit 2002;8: 165-177.

12 El-Agnaf OM, Salem SA, Paleologou KE, Curran MD, Gibson MJ, Court JA, Schlossmacher MG, Allsop D: Detection of oligomeric forms of alpha-synuclein protein in human plasma as a potential biomarker for Parkinson's disease. FASEB J 2006;20:419425.
13 Wilhelm KR, Yanamandra K, Gruden MA, Zamotin V, Malisauskas M, Casaite V, Darinskas A, Forsgren L, Morozova-Roche LA: Immune reactivity towards insulin, its amyloid and protein S100B in blood sera of Parkinson's disease patients. Eur J Neurol 2007; 14:327-334.

14 Gruden MA, Davudova TB, Malisauskas M, Zamotin VV, Sewell RDE, Voskresenskaya NI, Kostanyan IA, Sherstnev VV, MorozovaRoche LA: Autoimmune response to the amyloid structures of A $\beta$-amyloid peptide (2535) and human lysozyme in the serum of patients with progressive Alzheimer's disease. Dement Geriatr Cogn Disord 2004;18:165171.

15 Gruden MA, Davidova TB, Malisauskas M, Sewell RDE, Voskresenskaya NI, Wilhelm K, Elistratova EI, Sherstnev VV, MorozovaRoche LA: Differential neuroimmune markers to the onset of Alzheimer's disease neurodegeneration and dementia: autoantibodies to Abeta (25-35) oligomers, S100b and neurotransmitters. J Neuroimmunol 2007; 186:181-192.

16 Fahn S, Elton R, UPDRS Development Committee: Unified Parkinson's Disease Rating Scale; in Fahn S, Marsden C, Calne D, Goldstein M (eds): Recent Developments in Parkinson's Disease, vol 2. Florham Park, Macmillan Heathcare Information, 1987, pp 153 164.

17 Hoehn MM, Yahr MD: Parkinsonism: onset, progression and mortality. Neurology 1967; 17:427-442.

18 Xueen J, Gharibyan AL, Öhman A, Liu Y, Olofsson A, Morozova-Roche LA: Neuroprotective and nootropic drug noopept rescues $\alpha$-synuclein amyloid cytotoxicity. J Mol Biol 2011;414:699-712.

19 Rich RR, Fleisher TA, Shearer WT, Kotzin A: Clinical Immunology: Principles and Practice. St Louis, Mosby, 2001.

20 Mihara M, Uchiyama M: Determination of malonaldehyde precursor in tissues by thiobarbituric acid test. Anal Biochem 1987;86: 271-278.

21 Beauchamp C, Fridovich I: Superoxide dismutase: improved assays and an assay applicable to acrylamide gels. Anal Biochem 1971; 44:276-287.

22 Beers RF, Sizer IW: A spectrophotometric method for measuring the breakdown of hydrogen peroxide by catalase: J Biol Chem 1952;195:133-140.

23 Ilic TV, Jovanovic M, Jovicic A, Tomovic M: Oxidative stress indicators are elevated in de novo Parkinson's disease patients. Funct Neurol 1999;14:141-147.

24 Habig WH, Jakoby WB: Glutathione Stransferases (rat and human). Meth Enzymol 1981;77:218-231.
25 Malisauskas M, Zamotin V, Jass J, Noppe W, Dobson CM, Morozova-Roche LA: Amyloid protofilaments from the calcium-binding protein equine lysozyme: formation of ring and linear structures depends on $\mathrm{pH}$ and metal ion concentration. J Mol Biol 2003;330: 879-890.

26 LeVine $\mathrm{H}$ Jr, Thioflavine T: Interaction with synthetic Alzheimer's disease $\beta$-amyloid peptides: detection of amyloid aggregation in solution. Protein Sci 1993;2:404-410.

27 Graus F, Saiz A, Dalmau J: Antibodies and neuronal autoimmune disorders of the CNS. J Neurol 2010;257:509-517.

28 Polinsky R, McRae A, Baser SM, Dahlstrom A: Antibody in the CSF of patients with multiple system atrophy reacts specifically with rat locus ceruleus. J Neurol Sci 1991;106:96104.

29 Papachroni KK, Ninkina N, Papapanagiotou A, Hadjigeorgiou GM, Xiromerisiou G, Papadimitriou A, Kalofoutis A, Buchman VL: Autoantibodies to alpha-synuclein in inherited Parkinson's disease. J Neurochem 2007; 101:749-756

30 O'Nuallain B, Wetzel R: Conformational Abs recognizing a generic amyloid fibril epitope. Proc Natl Acad Sci USA 2002;99:14851490.

31 O’Nuallain B, Hrncic R, Wall JS, Weiss DT, Solomon A: Diagnostic and therapeutic potential of amyloid-reactive IgG antibodies contained in human sera. J Immunol 2008; 176:7071-7078.

\$2 Barbour R, Kling K, Anderson JP, Banducci K, Cole T, Diep L, Fox M, Goldstein JM, Soriano F, Seubert P, Chilcote TJ: Red blood cells are the major source of alpha-synuclein in blood. Neurodegener Dis 2008;5:55-59.

33 Lundblad M, Decressac M, Mattsson B, Björklund A: Impaired neurotransmission caused by overexpression of $\alpha$-synuclein in nigral dopamine neurons. Proc Natl Acad Sci USA 2012;109:3213-3219.

34 Graeber MB: Biomarkers for Parkinson's disease. Exp Neurol 2009;216:249-253.

35 Bertoncini CW, Jung YS, Fernandez CO, Hoyer W, Griesinger C, Jovin TM, Zweckstetter M: Release of long-range tertiary interactions potentiates aggregation of natively unstructured $\alpha$-synuclein. Proc Natl Acad Sci 2005; 105:1430-1435.

36 Spillantini MG, Crowther RA, Jakes R, Hasegawa M, Goedert M: Alpha-synuclein in filamentous inclusions of Lewy bodies from Parkinson's disease and dementia with Lewy bodies. Proc Natl Acad Sci USA 1998; 95:6469-6473.

37 Stefani M, Dobson CM: Protein aggregation and aggregate toxicity: new insights into protein folding misfolding diseases and biological evolution. J Mol Med 2003;81:678-699. 
-38 Nunomura A, Moreira PI, Lee HG, Zhu X, Castellani RJ, Smith MA, Perry G: Neuronal death and survival under oxidative stress in Alzheimer and Parkinson diseases. CNS Neurol Disord Drug Targets 2007;6:411-423.

39 O'Nuallain B, Freir DB, Nicoll AJ, Risse E, Ferguson N, Herron CE, Collinge J, Walsh D: Amyloid beta-protein dimers rapidly form stable synaptotoxic protofibrils. J Neurosci 2010;30:14411-14419.

-40 Benkler M, Agmon-Levin N, Shoenfeld Y: Parkinson's disease, autoimmunity, and olfaction. Int J Neurosci 2009;119:2133-2143.

-41 Masliah E, Rockenstein E, Adame A, Alford M, Crews L, Hashimoto M, Seuber P, Lee M, Goldstein J, Chilcote T, Games D, Schenk D: Effects of alpha-synuclein immunization in a mouse model of Parkinson's disease. Neuron 2005;46:857-868.

-42 Yamada T, McGeer PL, McGeer EG: Lewy bodies in Parkinson's disease are recognized by antibodies to complement proteins. Acta Neuropathol 1992;84:100-104.

-43 Orr CF, Rowe DB, Mizuno Y, Mori H, Halliday GM: A possible role for humoral immunity in the pathogenesis of Parkinson's disease. Brain 2005;128:2665-2674.

44 Hirsch EC, Hunot S: Neuroinflammation in Parkinson's disease: a target for neuroprotection? Lancet Neurol 2009;8:382-397.

$\checkmark 45$ Zipp F, Aktas O: The brain as a target of inflammation: common pathways link inflammatory and neurodegenerative diseases. Trends Neurosci 2006;29:518-527.
46 Wyss-Coray T: Inflammation in Alzheimer disease: driving force, bystander or beneficial response? Nat Med 2006;12:1005-1015.

47 Gao HM, Hong JS: Why neurodegenerative diseases are progressive: uncontrolled inflammation drives disease progression. Trends Immunol 2008;29:357-365.

48 Burwinkel M, Riemer C, Schwartz A, Schultz J, Niedhold S, Bamme T, Baier M: Role of cytokines and chemokines in prion infections of the central nervous system. Int J Dev Neurosci 2004;22:497-505.

49 Brown AR, Webb J, Rebus S, Walker R, Williams R, Fazakerley JK: Inducible cytokine gene expression in the brain in the ME7/CV mouse model of scrapie is highly restricted, is at a strikingly low level relative to the degree of gliosis and occurs only late in disease. J Gen Virol 2003;84:2605-2611.

50 Floden AM, Li S, Combs CK: Beta-amyloidstimulated microglia induce neuron death via synergistic stimulation of tumor necrosis factor alpha and NMDA receptors. J Neurosci 2005;25:2566-2575.

51 Eikelenboom P, Bate C, Van Gool C, Hoozemans JJ, Veerhuis R, Williams A: Neuroinflammation in Alzheimer's disease and prion disease. Glia 2002;40:232-239.

52 Pham C, Leong SL, Ali FE, Kenche VB, Hill AF, Gras SL, Barnham KJ, Cappai R: Dopamine and the dopamine oxidation product 5,6-dihydroxylindole promote distinct onpathway and off-pathway aggregation of alpha-synuclein in a $\mathrm{pH}$-dependent manner. J Mol Biol 2000;387:771-785.
53 Hattoria N, Wanga M, Taka H, Fujimura T, Yoritaka A, Kubo S, Mochizuki H: Toxic effects of dopamine metabolism in Parkinson's disease. Parkinsonism Relat Disord 2009; 15(suppl 1):S35-S38.

54 Jenner P: Oxidative stress in Parkinson's disease. Ann Neurol 2003;53(suppl):S26-S36.

55 Graham DG: Oxidative pathways for catecholamines in the genesis of neuromelanin and cytotoxic quinines. Mol Pharmacol 1978;14:633-643.

56 Conway KA, Rochet JC, Bieganski RM, Lansbury PT: Kinetic stabilization of the alpha-synuclein protofibril by a dopamine-alpha-synuclein adduct. Science 2001;9,294: 1346-1349.

57 Lotharius J, Brundin P: Pathogenesis of Parkinson's disease: dopamine, vesicles and alpha-synuclein. Nat Rev Neurosci 2005;3: 932-942.

58 Casetta A, Govoni V, Granieri E: Oxidative stress, antioxidants and neurodegenerative diseases. Curr Pharm Des 2005;11:20332052.

59 Watfa G, Dragonas C, Brosche T, Dittrich R, Sieber CC, Alecu C, Benetos A, Nzietchueng $\mathrm{R}$ : Study of telomere length and different markers of oxidative stress in patients with Parkinson's disease. J Nutr Health Aging 2011;15:277-281 